\title{
Conservación preventiva de documentos fotográficos con valor patrimonial
}

\section{Preventive conservation of photographic documents with heritage value}

\author{
Luis Ernesto Paz Enrique \\ luisernestope@uclv.cu
}

Universidad Central "Marta Abreu” de Las Villas, Cuba.

Beatriz del Sol Lorenzo

bdelsol@uclv.cu

Universidad Central "Marta Abreu" de Las Villas.

\section{Resumen}

La conservación preventiva de documentos se centra en otorgar condiciones óptimas a las fuentes para evitar su deterioro. Se plantean como objetivos 1) identificar los principales factores que inciden en las colecciones fotográficas que atesora la Sala de Historia de la Universidad Central "Marta Abreu" de Las Villas y 2) diseñar un plan de medidas de conservación preventiva para los materiales fotográficos del centro mencionado. El estudio se caracterizó por seguir una perspectiva metodológica mixta con la aplicación de métodos en los niveles teórico y empírico. Se identificaron los principales factores de deterioro de las colecciones fotográficas de la Sala de Historia de la Universidad Central "Marta Abreu" de Las Villas. Se diseñó un plan de medidas de conservación preventiva a partir de las características de las fuentes y del diagnóstico realizado. Los materiales fotográficos presentan características distintivas del resto de los documentos. El diseño de planes de conservación preventiva debe estar centrado en los resultados obtenidos en los diagnósticos que se realicen a las colecciones. Se identifican las características de los materiales fotográficos. Se realiza un estudio de caso para caracterizar los factores de deterioro que inciden en las colecciones fotográficas de la Sala de Historia de la Universidad Central "Marta Abreu" de Las Villas. Se enuncian acciones para favorecer la conservación preventiva de los materiales fotográficos. 


\title{
Palabras clave
}

Conservación preventiva de documentos, Patrimonio documental, Diagnóstico de conservación, Políticas de conservación.

\begin{abstract}
The preventive conservation of documents focuses on granting optimal conditions to the sources to avoid their deterioration. Is proposed as objectives 1) to identify the main factors that affect the photographic collections of the History Hall of the Universidad Central "Marta Abreu" de Las Villas and 2) to design a plan of preventive conservation for the photographic materials that it treasures of the mentioned center. The research classified as applied. The study was characterized to follow a mixed methodological perspective with the application of methods at the theoretical and empirical levels. Were identified the main deterioration factors of the photographic collections of the History Hall of the Universidad Central "Marta Abreu" de Las Villas. A plan of preventive conservation was designed based on the characteristics of the sources and the diagnosis made. Photographic materials have distinctive characteristics of the rest of the documents. The design of preventive conservation plans should be centered on the results obtained in the diagnoses that are made to the collections. Were identified the characteristics of photographic. A case study is carried out to characterize the deterioration factors that affect the photographic collections of the History Hall of the Universidad Central"Marta Abreu" Central University of Las Villas. Actions are announced to promote the preventive conservation of photographic materials.
\end{abstract}

\section{Keywords}

Preventive preservation of documents, Documentary heritage, Conservation diagnosis, Conservation policies.

Recibido: 21/04/2017

Aceptado: 4/06/2017

DOI: http://dx.doi.org/10.5557/IIMEI8-N14-089109

Descripción propuesta: PAZ ENRIQUE, Luis Ernesto; SOL LORENZO, Beatriz del, 2017. Conservación preventiva de documentos fotográficos con valor patrimonial. Métodos de Información, 8(14), pp. 89-109. 


\section{Introducción}

La conservación preventiva puede definirse como el otorgamiento de un nivel apropiado de seguridad, control ambiental y almacenamiento. Es la actividad asociada al mantenimiento de materiales de bibliotecas, archivos y museos para su uso en la forma física original o en algún otro formato. La rigurosidad de la preservación permite al documento evitar la restauración, siendo esta la última etapa para salvar el contenido del mismo. La composición orgánica de las fuentes influye en su conservación. Los documentos orgánicos están destinados al deterioro. Los factores ambientales, físicos, químicos, en adición al envejecimiento natural que se produce en las fuentes, provoca el deterioro y riesgo de pérdida del bien patrimonial.

\section{Conservación preventiva en colecciones bibliográficas patrimoniales}

Varios investigadores abordan la expresión patrimonio documental, Gutiérrez, et al. (2014) plantean que "los documentos patrimoniales deben poseer valor histórico, artístico, científico, literario y cultural para una comunidad”. El investigador Lobelle (2015) establece que la conservación documental se justifica por la importancia de las colecciones de documentos. Los estudios sobre la conservación del patrimonio bibliográfico y documental, "durante la última década han sido analizados por distintas disciplinas" (Palma, 2013).

Los investigadores Jaramillo y Marín (2014) establecen que "el documento bibliográfico patrimonial debe tener las características de originalidad (autenticidad), unicidad (irremplazable), valor simbólico, valor del contenido o valor estético". Algunas de las consecuencias que puede traer la desaparición de los documentos con valor patrimonial radica en que los mismos son "únicos y su desaparición es una pérdida clara y un empobrecimiento irreversible para la sociedad y la humanidad en su conjunto" (Riquelme, 2013).

Los principios clásicos de la conservación establecen que se deben conservar los documentos en su formato original como: documentos con valor legal o probatorio: libros raros y valiosos, manuscritos originales, documentos con valor estético, documentos cuyo formato facilite la investigación (mapas, planos, plegables, documentos de gran tamaño en general) (León, 2006). En los últimos años las investigaciones sobre conservación de documentos 
tradicionales ha disminuido atendiendo a la producción científica. Existe una tendencia por la conservación digital. Algunos autores que han abordado la temática son Batista, et al. (2015), Cabezas (2014), Cardoso, (2014), Giménez (2015), Paz y Hernández (2015), Paz, et al. (2016), Martí et al. (2016), Muñoz y Nogueras (2014), Ramírez y Rodríguez (2016). Los programas de conservación preventiva deben partir de la investigación. La identificación de las características de los soportes, el grado de deterioro, condiciones de almacenamiento y el grado de usabilidad son determinantes para la definición de políticas de conservación.

\section{Los fondos fotográficos y su conservación}

El descubrimiento de la fotografía, conocida como heliografía en sus inicios cuenta con más de dos siglos de antigüedad. Los primeros experimentos se presumen que datan de finales del siglo XVIII. Su técnica se basa en los principios físicos de la óptica, la ciencia que estudia el comportamiento de la luz. A criterio de González (2014): su invención se atribuye al francés JosephNicéphoreNiepce, cuando logró fijar, después de varios intentos, la imagen desde su ventana de una mesa servida antes de una comida. Lo más trascendente del nuevo instrumento fue que, de una forma completamente mecánica, se pudo lograr una imagen semejante a la que se observaba.

A finales del siglo XIX se inventó la película en rollo y se dieron los primeros pasos para lograr el colorido natural de las imágenes en las fotos. En la sociedad actual la fotografía desempeña un papel importante como medio de información, como instrumento de la ciencia y la tecnología, como una forma de arte y una afición popular (González, 2014). Es imprescindible en los negocios de la industria, la publicidad, el periodismo gráfico y en muchas otras actividades. La ciencia emplea la fotografía como medio para demostrar y registrar los descubrimientos.

La conservación de imágenes fijadas en material fotográfico se centra fundamentalmente en estudios desarrollados a partir de las ciencias químicas, biológicas y especialmente en el área de las ciencias de la información. El profesional de la información es el encargado de la salvaguarda de la documentación con valor histórico y patrimonial. 
Los tipos de material fotográfico son las microformas, microfilm, microfichas, la película cinematográfica y la fotografía propiamente dicha. La composición química del material fotográfico es la que más incide en el deterioro. Actualmente el papel fotográfico se clasifica en baritado (o clásico) y el plastificado. Aunque el deterioro es un proceso continuo y natural, hay muchas medidas que se pueden tomar para reducir la tasa a la cual estos procesos suceden y afectan las imágenes fotográficas. El proceso de develado de las imágenes se realiza con varias sustancias químicas que quedan impregnadas en el soporte. En cada etapa se emplean diversos materiales y temperatura.

Las fotografías deterioradas pueden demandar métodos de conservación técnicos que deben ser elaborados por un conservador profesional. Este procedimiento requiere experticia y tiempo. La restauración fotográfica demanda un alto costo monetario. Como opción, la preservación de las colecciones evita el deterioro de las fuentes. La preservación puede realizarse a través de la promoción de medidas de cuidado y manipulación apropiadas por medio de programas de educación a los trabajadores y usuarios. La utilización de embalajes de la mejor calidad (fundas, sobres y cajas) para su almacenamiento. A criterio de Vivar y Borrego (2014), es importante el mantenimiento de condiciones ambientales optimas en las áreas de depósito y exposición debido a que impide el innecesario deterioro de las imágenes.

\section{Problemática}

La Universidad Central "Marta Abreu" de Las Villas (UCLV) atesora documentos anteriores a su fundación en 1952. La documentación reviste gran importancia para la historia de la universidad, así como para la historia nacional. La institución fue declarada Monumento Nacional de la República de Cuba, donde influyó la documentación histórica y patrimonial que se atesora en el centro. Se han reportado, debido a malas prácticas con la documentación, extravíos y pérdidas totales de documentación. La documentación patrimonial en la actualidad se encuentra diseminada por varias áreas de la universidad ante la ausencia de locales adecuados para el almacenamiento. Existen varias colecciones fotográficas que reflejan la historia del centro que se encuentran almacenadas fundamentalmente en la Sala de Historial (SH) de la UCLV. 
El centro educacional se encuentra en la actualidad realizando gestiones para el funcionamiento, a nivel institucional, de un archivo central e histórico, al cual tributarán todas las áreas del centro. Ante tal situación cada área universitaria se encuentra realizando investigaciones para diagnosticar e identificar documentación con diverso valor y los factores de deterioro presentes en las colecciones documentales. Se realizan diagnósticos para proponer medidas preventivas a la documentación. La SH atesora la mayor parte del material fotográfico de tipo histórico de la universidad. Dicha institución carece de un diagnóstico de conservación que facilite la creación de políticas de conservación documental. El área carece de un plan de medidas preventivas para la conservación de los documentos.

\section{Objetivos}

1) Identificar los principales factores que inciden en las colecciones fotográficas que atesora la SH de la UCLV y 2) diseñar un plan de medidas de conservación preventiva para los materiales fotográficos que atesora la $\mathrm{SH}$ de la UCLV.

\section{Originalidad/valor}

El estudio favorecerá la identificación de los principales factores de deterioro que inciden en los materiales fotográficos. Se diseña un plan de conservación preventiva para los materiales fotográficos de la UCLV para proteger el patrimonio histórico, patrimonial y cultural que allí se deposita. La investigación contribuirá a mantener la declaratoria de Monumento Nacional del centro y a preservar la memoria histórica de la nación cubana y constituirá un instrumento con valor probatorio. Será de gran utilidad para toda la comunidad universitaria, así como para historiadores a nivel nacional.

\section{Materiales y métodos}

La investigación que se presenta, clasifica como investigación aplicada. Se enfoca en identificar el fenómeno y sus causas y ofrece una vía de solución a los problemas detectados de forma explícita. La investigación tiene un enfoque mixto, pero es eminentemente cualitativa.

Se emplean métodos y técnicas para la recogida de información. En el nivel 
teórico se utiliza el analítico-sintético, sistémico-estructural, histórico-lógico e inductivo-deductivo. En el nivel empírico se emplearon la observación, el análisis documental clásico y la encuesta. Las técnicas utilizadas fueron la entrevista, el cuestionario, guías de observación y la revisión bibliográfica. Para identificar las afectaciones de las colecciones se empleó la metodología desarrollada por el Modelo de la Biblioteca Nacional de Venezuela. Se emplea esta herramienta por su funcionalidad para identificar los elementos que influyen en la conservación de colecciones. Las variables de la planilla se pueden observar la Tabla 1.

\begin{tabular}{|l|l|}
\hline Variable & Descripción \\
\hline Sede & Se refiere al espacio físico de la entidad \\
\hline Depósito & Características físicas del depósito \\
\hline Mobiliario & Condiciones físicas del mobiliario \\
\hline $\begin{array}{l}\text { Condiciones ambientales } \\
\text { del depósito }\end{array}$ & $\begin{array}{l}\text { Condiciones de iluminación, ventilación, temperatura y } \\
\text { humedad relativa }\end{array}$ \\
\hline $\begin{array}{l}\text { Condiciones generales de la } \\
\text { colección }\end{array}$ & $\begin{array}{l}\text { Se refiere a la identificación de los factores de deterioro } \\
\text { identificados }\end{array}$ \\
\hline $\begin{array}{l}\text { Medidas de prevención } \\
\text { existentes }\end{array}$ & $\begin{array}{l}\text { Medidas contra catástrofes, insectos y roedores, políticas } \\
\text { para la consulta de la documentación, seguridad y vigilancia }\end{array}$ \\
\hline
\end{tabular}

Tabla 1. Variables analizadas en el Modelo de la Biblioteca Nacional de Venezuela (Fuente: Paz y Hernández, 2017).

La población se constituye por el total de alrededor de 10000 materiales fotográficos entre analógicos y digitales, de los cuales unas 8020 fotografías son analógicas. Para este estudio solamente se analizan las fotografías tradicionales que fueron obtenidas a partir de procesos físico-mecánicos y químicos de develado. La muestra seleccionada es de 5065 fotografías analógicas atesoradas en la institución. La muestra seleccionada asegura una representatividad del 50+1 \% de los documentos. Debe tenerse en cuenta que hay colecciones muy extensas y otras con pocos fondos documentales. Para garantizar la representatividad, la muestra "clasifica como no probabilística por conveniencia" (Hernández et al. 2010), en este caso, aunque toda la población tiene la posibilidad de formar parte de la muestra, se seleccionan aquellas que componen parte de conjuntos de la población general. Las cuotas seleccionadas por colecciones se muestran en la Tabla 2.

\begin{tabular}{|l|c|c|c|c|}
\hline Colecciones & $\begin{array}{c}\text { Período } \\
\text { que abarca }\end{array}$ & $\begin{array}{c}\text { Cantidad de } \\
\text { ejemplares }\end{array}$ & $\begin{array}{c}\text { Muestra } \\
\text { seleccionada }\end{array}$ & $\mathbf{\%}$ \\
\hline Etapa fundacional & $1948-1958$ & 292 & 292 & 100 \\
\hline
\end{tabular}




\begin{tabular}{|c|c|c|c|c|}
\hline $\begin{array}{l}\text { Presencia del Che } \\
\text { en la universidad }\end{array}$ & $1958-1960$ & 368 & 200 & 54 \\
\hline $\begin{array}{l}\text { Reforma } \\
\text { universitaria }\end{array}$ & $1959-1962$ & 407 & 250 & 61 \\
\hline $\begin{array}{l}\text { Ampliación de la } \\
\text { universidad }\end{array}$ & $1962-1972$ & 1526 & 800 & 52 \\
\hline $\begin{array}{l}\text { Milicias } \\
\text { universitarias y } \\
\text { lucha contra } \\
\text { bandidos }\end{array}$ & $1962-1970$ & 498 & 300 & 60 \\
\hline Beca universitaria & 1962-1980 & 574 & 400 & 70 \\
\hline $\begin{array}{l}\text { Reparto } \\
\text { universitario }\end{array}$ & 1980-1986 & 761 & 450 & 59 \\
\hline $\begin{array}{l}\text { Área de los } \\
\text { Camilitos }\end{array}$ & $1980-2016$ & 522 & 300 & 57 \\
\hline $\begin{array}{l}\text { Extensión } \\
\text { universitaria }\end{array}$ & $1952-2016$ & 817 & 500 & 61 \\
\hline $\begin{array}{l}\text { Actos, eventos y } \\
\text { ceremonias }\end{array}$ & $1952-2016$ & 714 & 400 & 56 \\
\hline $\begin{array}{l}\text { Doctores Honoris } \\
\text { Causa }\end{array}$ & $1952-2016$ & 96 & 96 & 100 \\
\hline $\begin{array}{ll}\text { Visita de } \\
\text { personalidades }\end{array}$ & $1952-2016$ & 406 & 300 & 74 \\
\hline Jardín Botánico & $1954-2016$ & 377 & 377 & 100 \\
\hline $\begin{array}{ll}\text { Centros } & \mathrm{de} \\
\text { investigación } & \end{array}$ & $1970-2016$ & 662 & 400 & 60 \\
\hline \multicolumn{2}{|l|}{ Total } & 8020 & 5065 & 63 \\
\hline
\end{tabular}

Tabla 2. Muestra seleccionada para la realización del diagnóstico de conservación (fuente: elaboración propia).

Para examinar el estado de conservación de los documentos se aplicaron las técnicas de entrevista, cuestionario y observación directa. Ambas técnicas contribuyeron a indagar sobre: condiciones constructivas del inmueble, incidencia de factores biológicos, incidencia de factores ambientales, existencia de un plan de prevención contra catástrofes, tipo de almacenamiento, cómo están colocados los documentos y los estantes, qué tipo de estantería se utiliza, cómo se realiza el préstamo o consulta de los fondos, cómo es la conservación en la sala examinada, qué tipo de materiales se almacenan y conservan y la actualización de las fichas conservación.

Se emplearon para la identificación de las afectaciones en los documentos, la leyenda de términos y abreviaturas elaborada en los Programas Diagnos y 
Fotodiagnos del Instituto de Historia de Cuba. Diagnos y Fotodiagnos son programas automatizados que se pueden utilizar para diagnosticar el estado de conservación de las colecciones de documentos con soporte en papel y fotográfico. Es el resultado de varios investigadores del Laboratorio de Restauración del Instituto de Historia de Cuba, además de otros profesionales de la Oficina Cubana de Propiedad Industrial. Los términos y abreviaturas de dichos programas pueden observarse en la Ilustración 1.

\begin{tabular}{|c|c|c|c|c|c|}
\hline \multicolumn{2}{|c|}{ Parámetros (leyenda) } & \multicolumn{2}{|c|}{ Parámetros (leyenda) Cont. } & \multicolumn{2}{|c|}{ Parámetros (leyenda) Cont. } \\
\hline PM & Pulpa Mecánica & Frag. & Fragmentado & $\mathbf{A}$ & Amarillamiento \\
\hline PQ & Pulpa Química & $\mathbf{R}$ & Rotura & Emb. & Emborronado \\
\hline PT & Pulpa de Trapo & D & Doblez & Emp. & Empalidecido \\
\hline Est. & Estucado & Perf. & Perforación & Ileg & Ilegible \\
\hline $\mathbf{O}$ & Otros & $\mathbf{C A}$ & Cinta Adhesiva & $\mathbf{C}$ & Corrosión \\
\hline $\mathbf{I}$ & Impreso & PP & Papel pegado & $\mathbf{O}$ & Otros \\
\hline G & Grafito & AH & Adherencia Hojas & HL & Hongo Local \\
\hline MTA & Metaloácido & MOL & Mancha Oxido (local) & HD & Hongo Difundido \\
\hline Sint. & Sintético & MOD & Mancha Oxido Difundido & Pig & Pigmentación \\
\hline TCh & Tinta China & MA & Manchas de Agua & Desp & Desprendimiento \\
\hline $\mathbf{M}$ & Mecanográfico & Fox & Foxing & PI & Presencia de Insectos \\
\hline $\mathbf{P}$ & Pictórico & OM & Otras Manchas & PR & Presencia de roedores \\
\hline $\mathbf{O}$ & Otros & $\mathbf{S}$ & Suciedad & Exc. & Excrementos \\
\hline Reb & Reblandecido & Acid. & Acidez & Abr & Abrasión \\
\hline $\mathbf{F}$ & Faltante & & & Rest & Restaurado \\
\hline
\end{tabular}

Ilustración 1. Abreviaturas utilizadas para el diagnóstico de conservación de documentos orgánicos en los Programas Diagnos y Fotodiagnos (Fuente: Instituto de Historia de Cuba).

\section{Resultados y discusión}

\subsection{Análisis del dominio}

El local que actualmente ocupa la SH de la UCLV pertenece a unos de los tres edificios fundacionales de la universidad. En la $\mathrm{SH}$ se atesoran valiosos patrimonios históricos y culturales. En la primera sala de la institución, el comandante Ernesto "Che" Guevara estableció su comandancia para la posterior toma de Santa Clara. La SH tiene como misión la de ofrecer servicios informativos, históricos e investigativos a la comunidad universitaria y al público interesado en la historia de la UCLV (Cruz, 2014).

A partir del 2012 en al SH comienzan a realizarse acciones con el propósito de cambiar positivamente la imagen de la institución. Se acordó la creación de un grupo de trabajo de historia. Fomentar exposición gráfica y muestra de objetos en exposiciones transitorias. Habilitar un almacén para el cuidado y conservación del mobiliario y documentación acordando para ello la 
climatización de la SH. Fueron acuerdos también la utilización de los aportes de estudiantes de carreras afines como Ciencias de la Información, Comunicación Social, Sociología y Periodismo, tanto en su período de trabajo social como práctica laboral, de forma tal que pudieran contribuir en lo referente a las actividades de mantenimiento de la SH. Durante el año 2013 se dio seguimiento al proyecto, sin embargo no todos los acuerdos fueron cumplidos, fundamentalmente aquellos en relación a la conservación de documentos.

\subsection{Estado de conservación de los materiales fotográficos que atesora la SH de la UCLV.}

Atendiendo a la variable sede, se puede establecer que la UCLV se encuentra ubicada en la región central de la República de Cuba. Es un centro de educación superior que forma profesionales en pregrado de 55 especialidades de las ciencias técnicas, exactas, sociales y humanísticas. Tiene un amplio programa de formación postgraduada, por lo que genera gran documentación que se almacena en las secretarías de cada facultad y que posteriormente pasa a formar parte de los fondos del archivo central de la universidad.

La UCLV fue fundada en 1952, siendo la tercera universidad fundada en Cuba. Las primeras edificaciones de la universidad se levantaron siguiendo la tendencia del movimiento moderno predominante en esos años. Se utilizaron los nuevos materiales industriales surgidos en el siglo XX como el hormigón armado, el acero laminado y el vidrio plano en grandes dimensiones. Las edificaciones se caracterizan por tener plantas y secciones ortogonales, generalmente asimétricas, ausencia de decoración en las fachadas y grandes ventanales horizontales conformadas por perfiles de acero. Los espacios interiores son luminosos y diáfanos. Se utiliza circulaciones verticales en las escaleras para destacar la volumetría del edificio, se logra la simbiosis entre las construcciones y la naturaleza. Las construcciones de la universidad juegan con el relieve ondulado del terreno para definir las diferentes plantas de los edificios. A diferencia de los colegios tradicionales, las edificaciones de la UCLV fueron pensadas para aprovechar la iluminación natural.

El local que ocupa el archivo de la SH de la UCLV posee varios aspectos que atentan contra a conservación de los documentos que se almacenan. Las colecciones documentales existentes en el local se componen de material 
fotográfico, documentación libraria, objetos de metal, objetos compuestos por fibras de tela, afiches y objetos de madera. Existen además documentos de diverso tipo relacionado con la historia de la universidad. El local para el almacenamiento está ubicado en el sótano del edificio conocido como la letra L. En la edificación se encuentran: la Dirección de Marxismo e Historia, un área para reuniones denominada Salón Verde, la Dirección de Extensión Universitaria de la Sede Central, el Departamento de Extensión Universitaria y la SH. En el piso superior se encuentran los departamentos docentes de Farmacia y Preparación para la Defensa, laboratorios de la Facultad de Química Farmacia y un laboratorio de la Facultad de Matemática-FísicaComputación. En el último piso superior de la edificación se encuentra la dirección del Centro de Bioactivos Químicos.

En los pisos superiores se labora con material químico y radioactivo, por lo que esto representa riesgo de afectación a los documentos teniendo en cuenta que pudiera ocurrir un accidente. El local colinda en su parte trasera con un baño para los trabajadores del edificio, aspecto que eleva la humedad relativa (HR) y acelera los procesos de deterioro en el depósito.

Atendiendo a la variable: depósito, el archivo cuenta dos locales pequeños y uno más grande que es donde están almacenado los documentos. El local se inunda ante la presencia de lluvias medias y grandes. El local presenta una ventana de cristal con marco metálico donde se observa la entrada de vegetación. El local presenta una salida a los otros dos más pequeños. En el acceso a estos locales se evidencia constantes caídas de agua producto a una turbina para el almacenamiento de agua en los pisos superiores. Se identifica una tubería de agua que atraviesa todo el local, además de peligro de incendio por identificarse redes eléctricas descubiertas y en mal estado.

Se observan manchas en las paredes productos a la humedad, además de un alto grado de hacinamiento de los documentos que no se corresponde con el espacio con que cuenta el archivo. La Ilustración 2 muestra el depósito de documentos y su riesgo al encontrase en un sótano cuyas paredes están bajo en nivel de la tierra, además de los posibles daños por accidentes. 


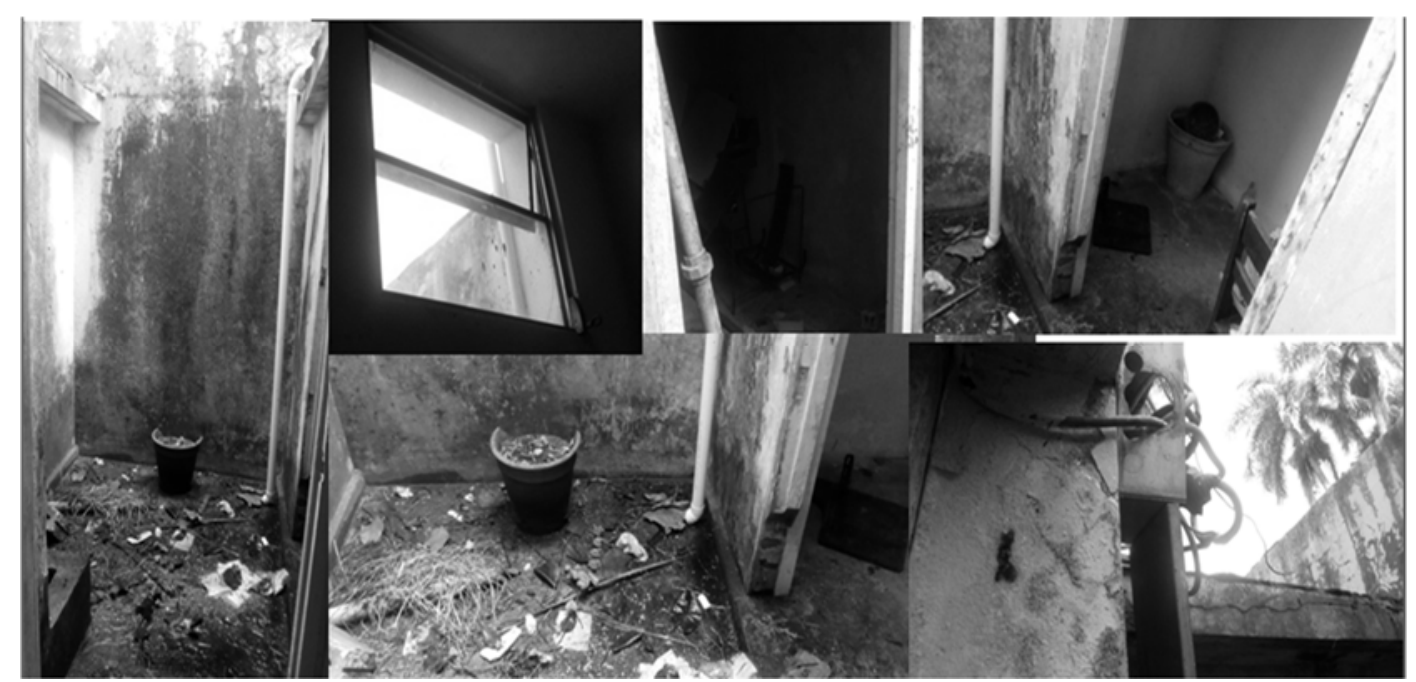

Ilustración 2. Afectaciones en la sede en donde se encuentran almacenadas las fotografías (fuente: elaboración propia).

La institución cuenta con personal de seguridad nocturno por lo que se evita el hurto y la entrada de personas no autorizadas en el local, aunque en muchas ocasiones el agente de seguridad no asiste al local. El personal que atiende el archivo son los trabajadores de la SH que radican en el DEU. El personal no cuenta con el conocimiento necesario para velar por la conservación, almacenamiento y organización adecuada de las colecciones fotográficas.

El archivo carece de equipos controladores del clima y no cuenta con una climatización que posibilite una temperatura estable. Los locales no están adecuadamente limpios al igual que la documentación que presenta polvo en casi su totalidad. Se emplea iluminación artificial y natural. La iluminación artificial que se emplea es un tubo fluorescente sin protector. En el depósito incide directamente la luz solar a través de las ventanas presentes en el local. El depósito se encuentra cerrado la mayor parte del tiempo.

Atendiendo a la variable: mobiliario, se identifica el empleo de 1 estantería ferrosa con presencia de óxido. La mayor parte de la estantería se encuentra sucia. Se identifica que no se posee la cantidad de estantería necesaria para el almacenamiento. Mucha documentación se encuentra en cajas sobre mesas y sillas. Se identifica, además, cuatro estantes de cartón de bagazo; material altamente degradable ante la alta HR y con PH ácido. La estantería empleada para el almacenamiento se muestra en la Ilustración 3. 


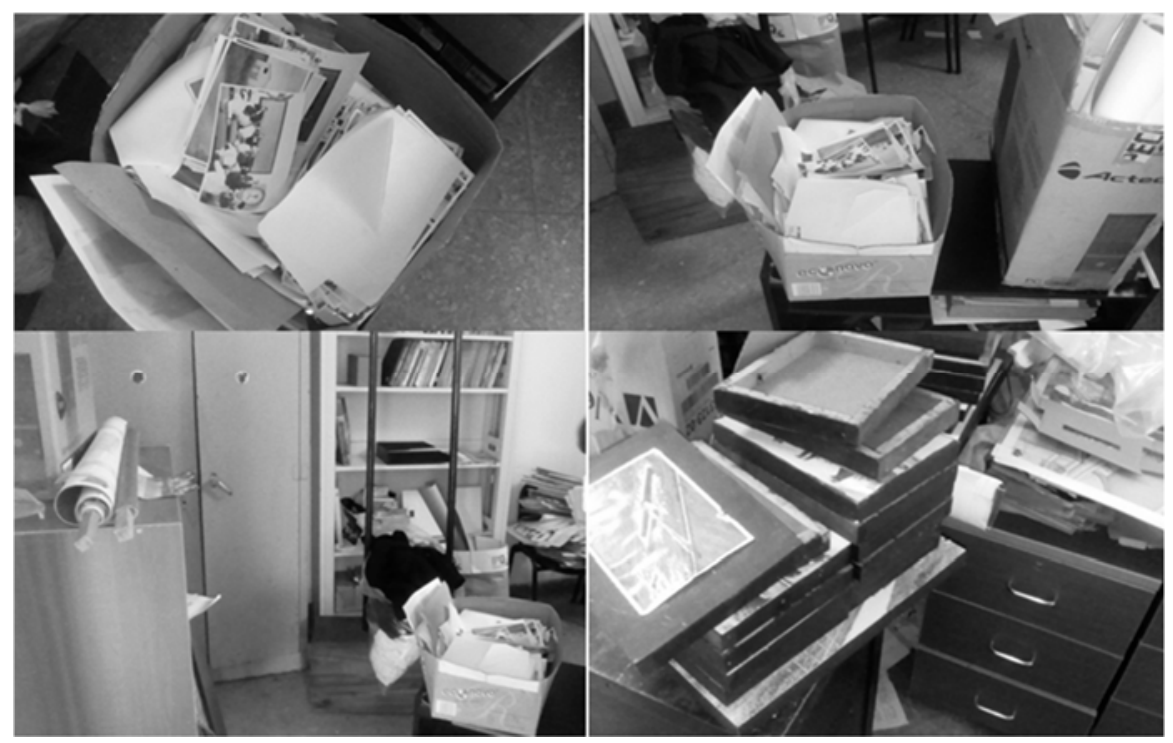

Ilustración 3. Estantería empleada para el almacenamiento de los materiales fotográficos (fuente: elaboración propia).

El depósito se encuentra alejado de la costa por lo que no existe salubridad en el ambiente. Está poco ventilado ante la presencia de pocas ventanas o climatización artificial. La época de lluvia representa un peligro real para la conservación de la documentación ante las inundaciones. Ante la lluvia el agua penetra en la institución por la ventana que existe en el depósito y la puerta principal del archivo. En el depósito se almacenan objetos ajenos a la documentación como tejidos, mesas y otros materiales. El ambiente es proclive para el desarrollo de microorganismos patógenos, insectos y roedores.

Se puede establecer que las colecciones de documentos carecen de ser procesados según las normas y procederes internacionales para el análisis documental. El criterio anterior provoca mayor manipulación de los documentos y por tanto mayor deterioro. La antigüedad de la documentación data desde años antes de la fundación de la universidad en 1952 hasta la actualidad. Las fechas extremas son desde el 1948 hasta el 2016. Toda la fotografía que se conserva de tipo analógica obtenida por los procesos de develado tradicionales. Se evidencia mala práctica en el almacenamiento de los documentos en casi la totalidad de las fuentes. Las condiciones del almacenamiento se muestran en la Ilustración 4. 


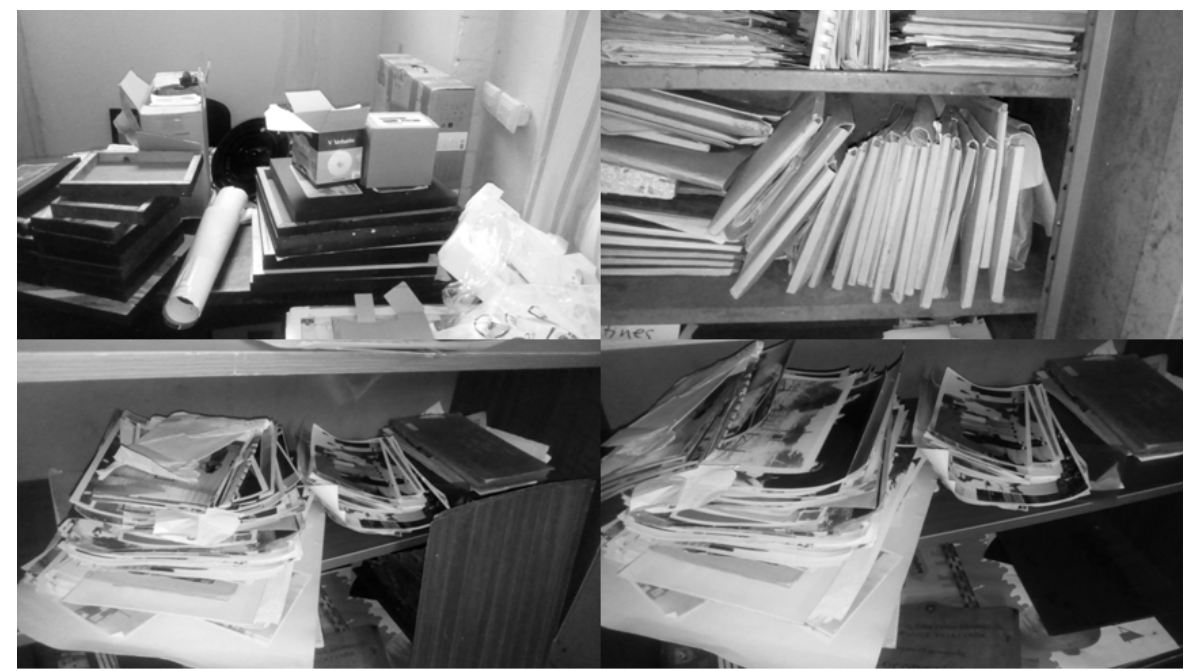

Ilustración 4. Malas prácticas de almacenamiento en el depósito (fuente: elaboración propia).

El tipo de soporte que es utilizado es el cartón o soporte fotográfico. Los documentos poseen valor probatorio, documental e histórico y si se eliminan, pueden derivarse prejuicios para la organización, dado que se consideran información pública. Esta documentación posee información valiosa en cuanto a lo patrimonial, histórico y documental. Para el diagnóstico de cada documento, se le asignó un número a cada fuente para su ubicación e identificación en la Tabla de Parámetros realizada. Se realizó una descripción de los documentos analizados destacando aspectos relacionados con el valor y composición de los documentos.

La Tabla de parámetros se realiza a partir de las abreviaturas reflejadas en la iError! No se encuentra el origen de la referencia., provenientes del Programa Diagnos y Fotodiagnos del Instituto de Historia de Cuba. El procesamiento estadístico permitió sistematizar varios aspectos de la documentación. Se identifican varios factores de deterioro, que pueden observarse en la Ilustración 5. 


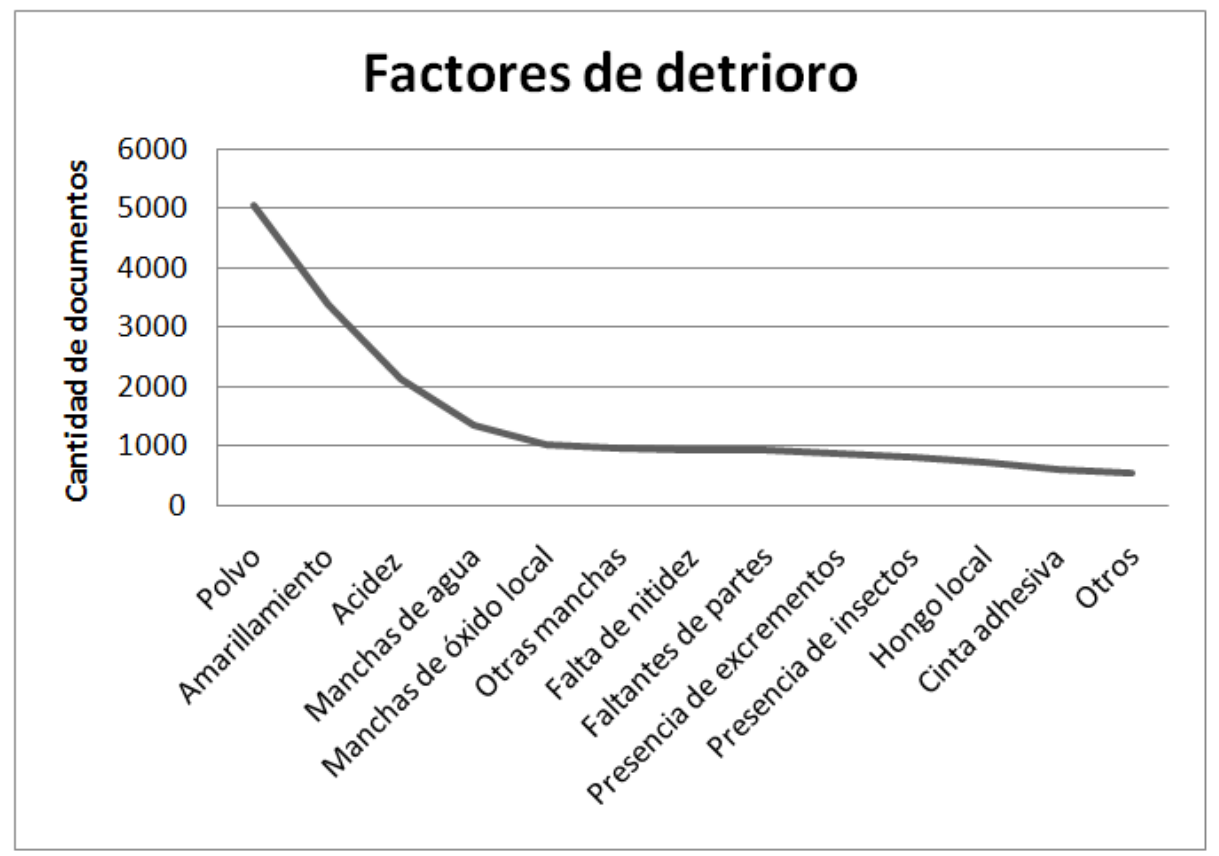

Ilustración 5. Factores de deterioro identificados en las colecciones fotográficas (fuente: elaboración propia).

Existen varios factores químicos condicionados por el almacenamiento. Se evidencia la presencia de varias fotografías que se han fusionado entre sí, producto de la HR y de las reacciones químicas del material. Debido a la HR alta y la falta de climatización del local, se observan enzimas gelatinosas en los materiales. Estas enzimas se identifican a partir de que varios documentos, pues están pegajosos y se fusionan con otros. Se observa efecto abrasivo en el material a partir de la alta cantidad de polvo en el local. Se identifican varias fotografías que fueron pegadas en cartón con cola animal, cuestión que favorece la acidez de los documentos y reacciones químicas adversas. Algunas afectaciones a los documentos se muestran en la Ilustración 6.

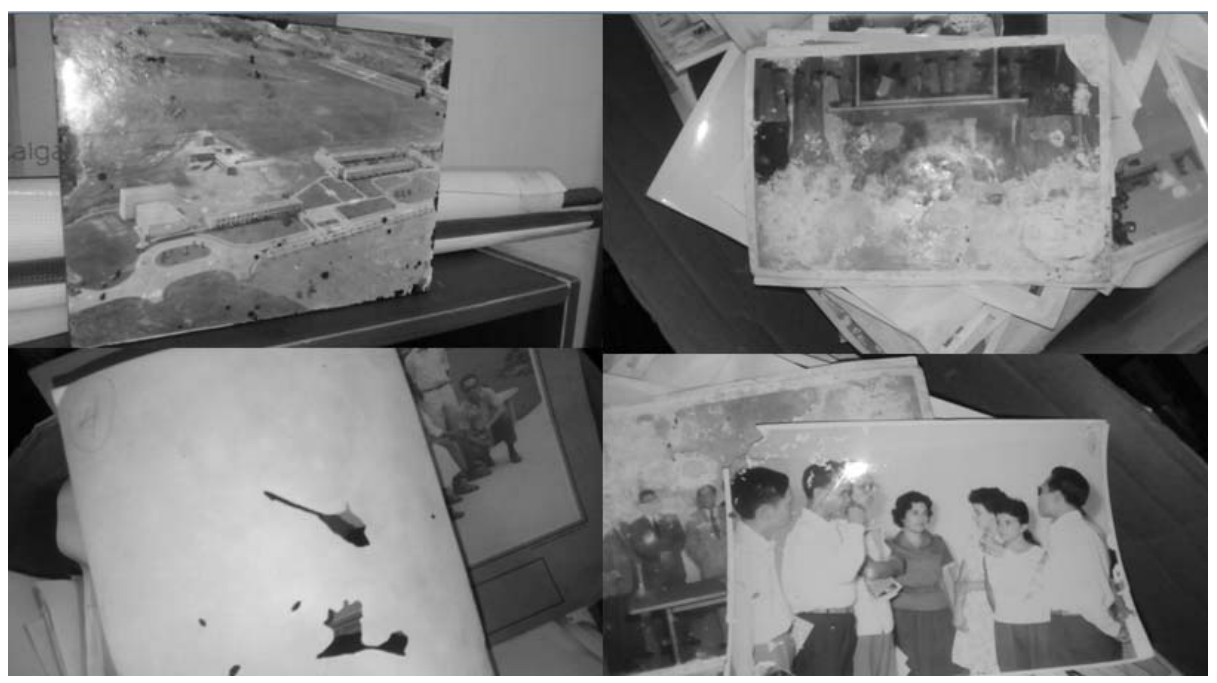

Ilustración 6. Afectaciones a los documentos (fuente: elaboración propia). 
La presencia de excrementos valida la existencia de roedores, factor que se comprueba al verificarse marcas en otras colecciones que atesora la institución. A pesar de las afectaciones descritas, los documentos, en su mayoría pueden consultarse y pueden ser utilizados. La valoración general de la colección es de regular, aunque con las afectaciones detectadas se pronostica que pueda ser malo en un período no mayor de 3 años. La evaluación del estado de conservación de la documentación se observa en la Tabla 3.

\begin{tabular}{l|l|c|}
\hline Clasificación & Cantidad de documentos \\
\hline Bien & 972 \\
\hline Regular & 3468 \\
\hline Mal & 625 \\
\hline
\end{tabular}

En el depósito está prohibido fumar. El archivo no cuenta con extintores de incendios. El archivo carece de un plan de evacuación ante inundaciones y catástrofes naturales o provocadas por el hombre. Poseen un plan de evacuación ante el estado de guerra insertado en el plan universitario, pero no particularizado a las necesidades de la documentación.

8.3. Plan de medidas de conservación preventiva para los materiales fotográficos que atesora la SH de la UCLV

Previo al diseño de un plan de medidas, es necesario establecer los principios básicos en los que debe sustentarse la conservación preventiva de documentos de tipo fotográfico. La planificación debe ser una premisa fundamental para la creación de condiciones óptimas que alarguen la vida de los documentos. A criterio de León (2006) la edificación que se destine para el almacenamiento de cualquier fondo documental debe tener como elementos primarios: limpieza, ventilación adecuada, sin filtraciones o exceso de humedad, climatización, sin plagas de insectos o microorganismos, diseño de iluminación acorde a los documentos, instalaciones hidráulicas y eléctricas seguras. La preparación del personal, el mobiliario y la creación de estrategias y medidas contra posibles daños son otros de los aspectos a tener en cuenta en una política de conservación.

A partir de los postulados anteriores, la solución más viable para la conservación de los documentos que atesora la SH de la UCLV es un cambio de local. El depósito corre riesgo al estar situado en un sótano y tener en pisos 
superiores áreas en las que se labora con material químico y radioactivo. La creación de una nueva sede con condiciones óptimas y personal capacitado, garantizará que los documentos perduren por más tiempo. Esta opción resulta poco viable para los trabajadores de la $\mathrm{SH}$ teniendo en cuenta que no hay mayor disponibilidad de locales. El acondicionamiento del local en el que actualmente se atesoran los fondos fotográficos patrimoniales de la UCLV y la conservación documental deberá regirse por el siguiente plan de medidas:

1. Hermetizar el local para evitar que la contaminación del ambiente y posibles sustancias como gases, polvo penetren y dañen los documentos. Se debe colocar una barrera de 20 a $25 \mathrm{~cm}$ para evitar que entre agua en época de lluvia. Las ventanas deben ser reparadas y las paredes deben ser recubiertas con pintura absorbente.

2. Climatizar el local y adquirir equipos controladores y medidores de clima como: deshumificador, psicrómetro y termohidrógrafo. Es necesaria la adquisición de varios deshumificadores debido a la alta HR del local al estar en un sótano y cercano a un baño. El funcionamiento de estos equipos debe ser permanente para evitar las fluctuaciones de temperatura.

3. Cerrar el baño de trabajadores para minimizar los daños por HR en los documentos.

4. Se debe eliminar la tubería de agua que atraviesa el local para evitar un accidente. La turbina cercana debe ser cambiada de lugar.

5. Las redes eléctricas en mal estado deben ser reparadas para disminuir el riesgo de incendio. Deben colocarse implementos protectores en cada área donde exista cableado.

6. Debe garantizarse que los fondos cuenten con personal de seguridad para evitar el hurto, téngase en cuenta que la mayor parte de la documentación que se atesora es original con valor patrimonial.

7. Se propone un cambio de mobiliario para almacenar las fuentes. Las fotografías se deben colocar individualmente en crucetas de papel libre de ácido y estas en sobre o estuche de la misma calidad. Los sobres se colocarán verticales en cajas con calidad de archivos organizados por colecciones. Las cajas o contenedores se ubicarán en un armario metálico. La estantería metálica a adquirir deberá estar separada $25 \mathrm{~cm}$ de la pared y $50 \mathrm{~cm}$ del suelo y estar recubierta con un barniz protector con PH neutro. 
8. Garantizar la fumigación especializada cuando sea preciso, no fumigar más de dos veces al año y con los componentes químicos adecuados a los materiales.

9. Atendiendo al control integrado de plagas se debe establecer un sistema de vigilancia para detectar posibles afectaciones de microorganismos que puedan provocar daños a la documentación. Se debe realizar una sistemática revisión de las fuentes documentales con periodicidad mensual y con muestras diferentes, para identificar posibles afectaciones a los documentos por factores biológicos.

10. No ingerir alimentos en la sala, los restos de comida atraen a gran variedad de insectos, roedores y microorganismos.

11. Mantener la limpieza del local donde se almacenan las colecciones para favorecer la eliminación de polvo. Se recomienda destinar tres días a la semana para la limpieza del local.

12. Evitar ralladuras en el material orgánico, el especialista deberá velar por la integridad de la fuente documental y exigir el cumplimiento de las normas para el acceso y consulta a la documentación.

13. No utilizar productos químicos comerciales o de soluciones para la limpieza del local. Limpiar los documentos utilizando cepillos de cerdas suaves, siempre en dirección al piso para que el polvo vaya hacia abajo. De ser posible se propone la limpieza con una aspiradora de mano para evitar que los residuos caigan al suelo propiciando el menor movimiento de las partículas.

14. Evitar colocar sustancias adhesivas y escribir con plumones la superficie de la documentación, además del daño al documento se puede ocasionar una reacción química.

15. Evitar el contacto con otras superficies de diferente material, la composición de la colección documental es muy sensible debido a los procesos de develado. El contacto de las fotografías con materiales con diverso $\mathrm{PH}$ podría producir reacciones químicas que dañarían las fuentes.

16. Se deben colocar cortinas en las ventanas del local a fin de evitar el contacto directo de los rayos del sol y provocar acidez en el marial. Debe aprovecharse al máximo la luz natural.

17. Ofrecer cursos y talleres para los trabajadores y usuarios de la institución. El objetivo de los mismos debe ser el de socializar conocimiento sobre los planes de evacuación existentes, la 
conservación documental y las características de las fuentes de información orgánicas patrimoniales.

18. Contar con el asesoramiento especializado para llevar a cabo acciones de conservación, almacenamiento y organización adecuada de las colecciones fotográficas.

19. Elaborar y mantener actualizado un plan contra catástrofes (incendios, inundaciones, etc.) acorde las necesidades de las fuentes. El mismo debe ser revisado de forma semestral y solicitando los accesorios necesarios para la protección de la colección como extintores de incendio.

20. Se propone la confección de una política de acceso a los documentos de la colección, la misma deberá contener los requisitos mínimos para la consulta de fuentes originales en correspondencia con el estado de conservación de la fuente y el objetivo de su consulta.

21. Se aconseja la digitalización de las fotografías, de esta forma se evitaría la manipulación innecesaria y por tanto la perdurabilidad de las fuentes originales.

22. Ofrecer y promover el empleo de implementos que protejan la salud de los usuarios y especialistas que acceden a la colección.

23. Comprobar el estado de las fuentes antes y después del préstamo.

24. Elaborar y mantener actualizada la ficha de conservación de la documentación.

25. Procesar todos los fondos fotográficos para favorecer la rápida recuperación de los mismos y evitar la manipulación innecesaria.

\section{Conclusiones}

Los fondos bibliográficos patrimoniales reflejan las características de una nación. El diseño de planes de conservación debe partir de diagnósticos, propiedades y características de los documentos.

La fotografía como documento es altamente sensible por su composición química. Los materiales fotográficos que atesora la $\mathrm{SH}$ de la UCLV se encuentran expuestos a procesos continuos de deterioro. Los principales factores que inciden en los documentos es el almacenamiento inadecuado y bajo tierra, daños por una alta HR, presencia de insectos y roedores, inadecuada limpieza en el local y la carencia de equipos controladores de clima. 
El estado general de la colección es de regular. Se pronostica un deterioro progresivo de las fuentes a partir de las condiciones del depósito y los factores a los que están expuestas. Las condiciones de almacenamiento en combinación con los factores físico mecánicos asociado a la manipulación de las fuentes pueden provocar que se aceleren los procesos de deterioro.

Se diseña un plan de medidas preventivas encaminadas a preservar la documentación fotográfica de la SH de la UCLV. El plan de medidas está centrado en el diagnóstico de conservación realizado. Las medidas propuestas contribuirán a preservar la documentación, evitar la restauración y a mantener la historia de la UCLV y nacional.

\section{Agradecimientos}

Al Departamento de Extensión Universitaria por favorecer que se realizara la investigación. Al apoyo de la facultad de Matemática, Física y Computación por potenciar el desarrollo de este tipo de estudios en la formación de pregrado. Al proyecto Sistema de Superación en las Televisiones Locales para potenciar el Desarrollo Local (SSTv). Las instituciones y el proyecto mencionado pertenecen a la Universidad Central "Marta Abreu" de Las Villas, Cuba.

\section{Referencias bibliográficas}

BATISTA, A.N.; SUÁREZ, E. y OTERO, L., 2015. El proceso de descripción archivística en el Archivo de la Universidad de Ciencias Médicas de La Habana. Revista Cubana de Información en Ciencias de la Salud, 26(4), 394-404.

CABEZAS, C., 2014. Transparencia activa: Gestión de documentos electrónicos y datos en Chile. Serie Bibliotecologia y Gestión de Información, 93(2014), 1-15.

CARDOSO, G., 2011. Documento equivalente. En: Actualicese: investigación contable y tributaria en profundidad. [en línea]. 26 mayo 2011. [Consulta: 3/05/2017] Disponible en: http://actualicese.com/opinion/documento-equivalentegerardo-cardozo-rojas

CRUZ, M.E., 2014. Remodelación de la Sala de Historia de la Universidad Central "Marta Abreu" de Las Villas. Ponencia presentada en el X Taller Provincial de Extensión Universitaria. Santa Clara: Feijóo. 
GIMÉNEZ CHORNET, V., 2015. Normas ISO para la gestión de los documentos electrónicos: buenas prácticas para la gestión documental en las empresas. Fuentes, 9(40), 7-16.

GONZÁLEZ, L., 2014. Historia y evolución de la fotografía. La Habana: Editorial Científico Técnica.

GUTIÉRREZ, T. et al., 2014. Importancia del desarrollo de la colección de documentos patrimoniales en una institución del sector salud. Revista Cubana de Higiene y Epidemiología, 52(3), 1-10.

HERNÁNDEZ, R., FERNÁNDEZ, C. y BAPTISTA, P., 2010. Metodología de la Investigación. Ciudad de México: McGraw-Hill, Interamericana Editories

JARAMILLO, O. y MARÍN, S.A., 2014. Patrimonio bibliográfico en la biblioteca pública: memorias locales e identidades nacionales. El profesional de la información, 23(4), 425-432.

LEÓN, H.R., 2006. Almacenamiento, conservación y preservación de documentos. La Habana: Editorial Félix Varela.

LOBELLE, G., 2015. El patrimonio documental de la nación cubana: amparo jurídico en la legislación nacional e internacional. Revista Cubana de Información en Ciencias de la Salud, 26(4), 381-393.

MARTÍ, Y., DEL TORO, G. y GUTIÉRREZ, Y., 2016 Visibilidad y accesibilidad al patrimonio documental de la Universidad de La Habana: repositorio institucional SCRIPTORIUM. Bibliotecas. Anales de Investigación, 12(1), 30-40.

MUÑOZ, J.F. y NOGUERAS, J., 2014. La digitalización de documentos en la Administración de Justicia. Ibersid, 8, 49-53.

PALMA, J.M., 2013. El patrimonio cultural, bibliográfico y documental de la humanidad. Revisiones conceptuales, legislativas e informativas para una educación sobre patrimonio. Cuicuilco, 58, 31-57.

PAZ, L.E. y HERNÁNDEZ, E.A. 2015., Conservación de Soportes con Grabaciones Digitales por Medio de la Tecnología Óptica. Ciencias Holguín, 2, $1-14$.

PAZ, L.E. y HERNÁNDEZ, E.A., 2017. La gestión documental enfocada en la conservación preventiva de documentos. Bibliotecas, 35(1): 1-20.

PAZ, L.E., HERNÁNDEZ, E.A., IZQUIERDO, M. y BRITO, L., 2016. Fondos documentales del Archivo Parroquial de la Iglesia Católica "San Pedro y San Pablo" de Corralillo. Bibliotecas. Anales de Investigación, 12(1), 41-51.

RAMÍREZ, N. y RODRÍGUEZ, B., 2016. Conservación de información, un llamado de atención. Revista Publicando, 3(6): 352-361.

RIQUELME, J., 2013., Plan de recuperación del patrimonio documental de la comunidad judía de Chile. Cuadernos Judaicos, 30, 122-135.

VIVAR, I. y BORREGO, S., 2014. Las películas cinematográficas: su deterioro y conservación. Boletín del Archivo Nacional, 22: 62-76. 
